\title{
Assessing suicide ideation among older adults: a systematic review of screening and measurement tools
}

\author{
Helen Gleeson, ${ }^{1}$ (1) Chloe Roesch, ${ }^{2}$ Trish Hafford-Letchfield, ${ }^{3}$ (10) and Toby Ellmers ${ }^{4}$ \\ ${ }^{1}$ Middlesex University, London, UK \\ ${ }^{2}$ Nottingham Trent University, Nottingham, UK \\ ${ }^{3}$ University of Strathclyde, Glasgow, UK \\ ${ }^{4}$ Brunel University London, Uxbridge, UK
}

ABSTRACT

Objectives: Rates of suicide in older adults may be higher than reported due to poor understandings of presentation of suicide ideation in this group. The objectives of this paper were to (i) review current measurement tools designed for older adults to detect suicide ideation and (ii) assess their psychometric properties.

Design: We used a systematic review approach to identify measurement tools developed specifically for older adults without cognitive decline or impairment.

Results: Ten articles that reported on a total of seven different measurement tools were identified. These included tools that focused on resiliency to suicide and those that measured risk of suicide behavior. There was wide variation across the articles: some were adaptations of existing scales to suit older populations, others were developed by authors; they varied in length from four to 69 items; a range of settings was used, and there was a mix of self-report and clinician-administered measures. Most displayed good psychometric properties, with both approaches showing similar quality. Limitations in terms of samples, settings, and measurement design are discussed.

Conclusion: The case for specific measures for older adults is clear from this review. There appear to be unique factors that should be considered in understanding suicide ideation and behavior among older adults that may not be directly assessed in non-specific measurements. However, there is a need to expand the diversity of individuals included in measurement development to ensure they are appropriate across gender, culture and minority status, and for the views of professionals to be considered.

Keywords: Death and dying, Psychogeriatrics, Scales, Screening, Suicide

\section{Introduction}

The World Health Organization (WHO, 2019) calculates that one person dies by suicide approximately every 40 seconds worldwide, with those in older age groups (i.e. over 65 years) being at highest risk. Globally, older men are twice as likely to die by suicide compared to women in the same age groups (Barak et al, 2020; Canetto, 2017). Suicide ideation (thoughts, desires, or plans surrounding ending one's own life) is a recognized risk factor in suicidal behavior (Nock et al., 2008) and increases the risk

Correspondence should be addressed to: Helen Gleeson, Middlesex University, London, NW4 4BT, UK. Phone: + 44208441 4560. Email: h.gleeson@mdx .ac.uk. Received 15 Apr 2021; revision requested 09 Aug 2021; revised version received 07 Sep 2021; accepted 04 Oct 2021. First published online 19 November 2021. of suicide attempts in older adults (Pfaff and Almeida, 2005).

Research suggests that there may be unique factors that contribute to thoughts of suicide in older adults including social isolation, childhood trauma, financial distress, and multiple medical morbidities that are not routinely investigated (Almeida et al., 2012; De Leo et al., 2013). Evidence suggests that deaths in older people that result from more "passive" acts (e.g. voluntary stopping of eating and drinking, suspending/refusing medication) are unlikely to be formally investigated as potential suicide deaths and that official statistics therefore under-estimate the prevalence of suicide in those over 65 (Deuter et al., 2016; Hafford-Letchfield et al., 2018; Lachman, 2015). A key feature in preventing suicide among older adults is to 
accurately and routinely screen for suicide ideation. However, this is not currently the norm in healthcare settings (De Leo et al., 2013).

\section{Suicide and older adults}

Joiner's (2005) interpersonal theory of suicide posits that people consider suicide when they feel that they are a burden to family and/or society, and when they no longer feel they belong to valued relationships or wider groups. Suicide in later life is often considered to be the result of a "rational decision" and can be interpreted as a legitimate exit in the case of dramatic changes in social status and role (Bernier et al., 2020). Structural ageism and internalized stigma can contribute towards the view that depression is a normal feature of the aging process and the antecedent of an anticipated and definitive ending (Gleeson et al, 2018; Stanley et al, 2016). Compared to younger age groups, suicide behavior is also more likely to result in death in older people (MonforteRoyo et al, 2011; Wand et al, 2017).

Psychological autopsy reports have shown that a high proportion $(46-86 \%)$ of reported suicides in older people were correlated with symptoms of depression in the weeks prior to death (Conwell et al., 2011). A clinical diagnosis of depression or anxiety disorder was also found to be associated with a seven-fold increased risk of reporting suicide ideation compared to those without a diagnosis for over 65-year-olds (Almeida et al., 2012). It has been argued, however, that symptoms of depression among older people differ from those of younger adults and that there is a need for more age-specific screening and diagnostic measures (Conejero et al., 2018; Gleeson et al., 2018). Interventions aimed at identifying and reducing depression among older populations appear to have little long-term impact on mental health (Almeida et al., 2012; Gleeson et al., 2018). History of suicide behavior is recognized as a key indicator of taking one's life in older populations (O'Riley et al., 2014); however, such a history may not be present and their choice of means of suicide are more likely to be lethal in the first instance when compared to younger populations (WHO, 2019).

Cukrowicz et al. (2011) distinguished between suicide ideation and death ideation in older adults, which they described as a passive wish to die. Their study tested theory-based risk models of suicide including death ideation, depressive symptoms, thwarted belongingness, and perceived burdensomeness. Their findings suggest that perceived burdensomeness contributes unique variance to suicide ideation in older adults, comparable to that found in other studies with people with terminal illnesses. Feelings of being a burden to others and subsequent perceptions that death is a viable way to avoid this were also found to be present in other studies with older adults expressing passive suicide ideation and their carers (e.g. Hafford-Letchfield et al., 2018).

\section{Screening for suicide ideation in older adults}

Given the established links between depression and suicide across age groups, the most common approach to preventing suicide in older age groups to date has concentrated on measuring signs of depression (Gleeson et al., 2018). However, screening for depression in older people is not routine across settings (Gleeson et al., 2018) and numerous studies have highlighted a reluctance to speak openly about mental health among this generation (e.g. Hafford-Letchfield et al., 2018). In contrast, other research has suggested there is a preference for talking therapies among older people, but in the $\mathrm{UK}$ at least, access to these interventions remains low in this group (Frost et al., 2018). In practice, it has been reported that those over 85 years are up to a third more likely to be prescribed anti-depressants compared to those between 55 and 85 years (Frost et al., 2018).

However, it appears that a majority of older people who die by suicide have visited a GP in the previous 30 days (Neufeld and O'Rourke, 2009). The most common ailments discussed at these visits are somatic in nature rather than related to mental health. While it is recognized by GPs that older people may present with somatic symptoms that mask psychological difficulties, they may feel that the time and sensitivity needed to properly uncover and respond to these issues is not available to them (Frost et al., 2018). In addition, the normalization of older people's poor mental health as a factor of aging can lead to Health Care Professionals (HCPs) believing that therapeutic interventions are likely to be ineffective and therefore were less likely to be offered.

Accurate detection of suicide ideation among older adults is of particular relevance in light of arguments that death by suicide is likely to be under-reported in those over 65 (Deuter et al., 2016). The potential for unique presentation of depression or other mental health difficulties related to suicide ideation, the seeming reluctance to discuss psychological or emotional distress with healthcare professionals, and the possibility that poor mental health is a "normal" part of aging all may contribute to many older people failing to receive the support and preventative measures needed to reduce suicide. Currently, there is little consensus as to how to screen for suicide ideation in older people. It is likely that healthcare professionals either 
lack training in mental health problems in this population or are unaware of the need to assess the potential for suicide behavior in older people. The literature suggests a need for a common, easy to use, and acceptable means of accurately screening older people for both active and passive suicide ideation that can inform improved mental healthcare provision for this group.

To our knowledge, no comprehensive psychometric review of measurements of suicide ideation designed specifically for older adults has been conducted. Given the strong theoretical arguments that older adults may display unique, nuanced indicators of suicide ideation, it is important to consider the usefulness and efficacy of measures aimed at this population to better understand how to uncover, and respond, to suicide ideation in older adults. We conducted a systematic review of existing measures of suicide ideation designed for use with older adults to address the following aims:

1. Identify current measures of suicide ideation in older populations and to explore the extent and effectiveness of their use

2. Evaluate the psychometric properties of these measures and identify strengths and weaknesses in current provision to effectively measure suicide ideation in this population

\section{Methods}

\section{Search strategy}

HG and CR conducted searches in 12 databases (APA PsycTests; CareKnowledge; CINAHL; Cochrane; Emerald; IBSS; Medline; NICE evidence; OVID; PsycInfo; Social Care Online; Web of Science) using a combination of keywords based on the PICO system (searches conducted between June and August 2020).

Population: older; aged; geriatric; care home resident*; elderly; old; old age

Intervention: measure; questionnaire; survey; instrument; scale

Setting: care home; residential care; community; hospital; institutional care

Outcome: depression; suicide; suicidal thoughts; suicide thoughts; suicid* ideation; suicid* behavior; mental health; wish to die; well-being

\section{Inclusion/exclusion criteria}

Peer-reviewed journal articles were included if they reported on the development, testing, or validation of a measurement instrument designed to assess suicide ideation in older populations only. We excluded those articles that reported on scales intended to measure broader mental health-related factors but that may have included a single item to assess suicide ideation (e.g. Geriatric Depression Scale). We included articles that had been assessed with non-English speaking populations if the article was published in the English language. Studies were included irrespective of where the sample was drawn from to validate a measure (e.g. psychiatric inpatient, community, residential care, etc.). The term "older people" was defined as those 50 years and over to allow for the broadest range of studies to be included.

\section{Data extraction and quality assessment}

The initial database search yielded 123 papers with one duplicate. Titles were screened by two authors (HG and CR) for relevance with a remaining 46 included for second screening. Abstracts were read by at least two authors for a final decision on inclusion, leaving a total of ten articles, reporting on seven different scales, for review. Reference lists of each of these articles were also screened for any additional relevant articles to include, but did not yield any additional papers for inclusion. No disagreements on inclusion/exclusion occurred between the authors of this paper. This review was conducted in accordance with the Preferred Reporting Items for Systematic Reviews and Meta-Analysis (PRISMA; Moher et al., 2009). The PRISMA diagram can be found in Figure 1.

The COSMIN framework was used to evaluate the included studies for quality of psychometric reporting, with scoring included as recommended by Terwee et al. (2012), Table 2 details the quality assessment criteria applied in this study.

\section{Results}

\section{General results}

The main details of each of the articles reviewed, with abbreviations used throughout the results, are outlined in Table 1.

We identified seven individual scales across the ten articles included for review that were a mixture of those measuring negative (wish/will to die) factors and those focusing on reasons, or wishes, to live. The measures included the Reasons for Living scaleOlder Adults (RFL-OA), reported on by three of the articles included for review: an adaption by Edelstein et al. (2009) for older adults, a shortened version developed by Lutz et al., (2019), and one article examining the resiliency to suicide subscale individually (Wadhwa and Heisel, 2019). The psychometric properties of Geriatric Suicide Ideation Scale (GSIS) (which was originally developed by Heisel and Flett in 2006) were reported by two 


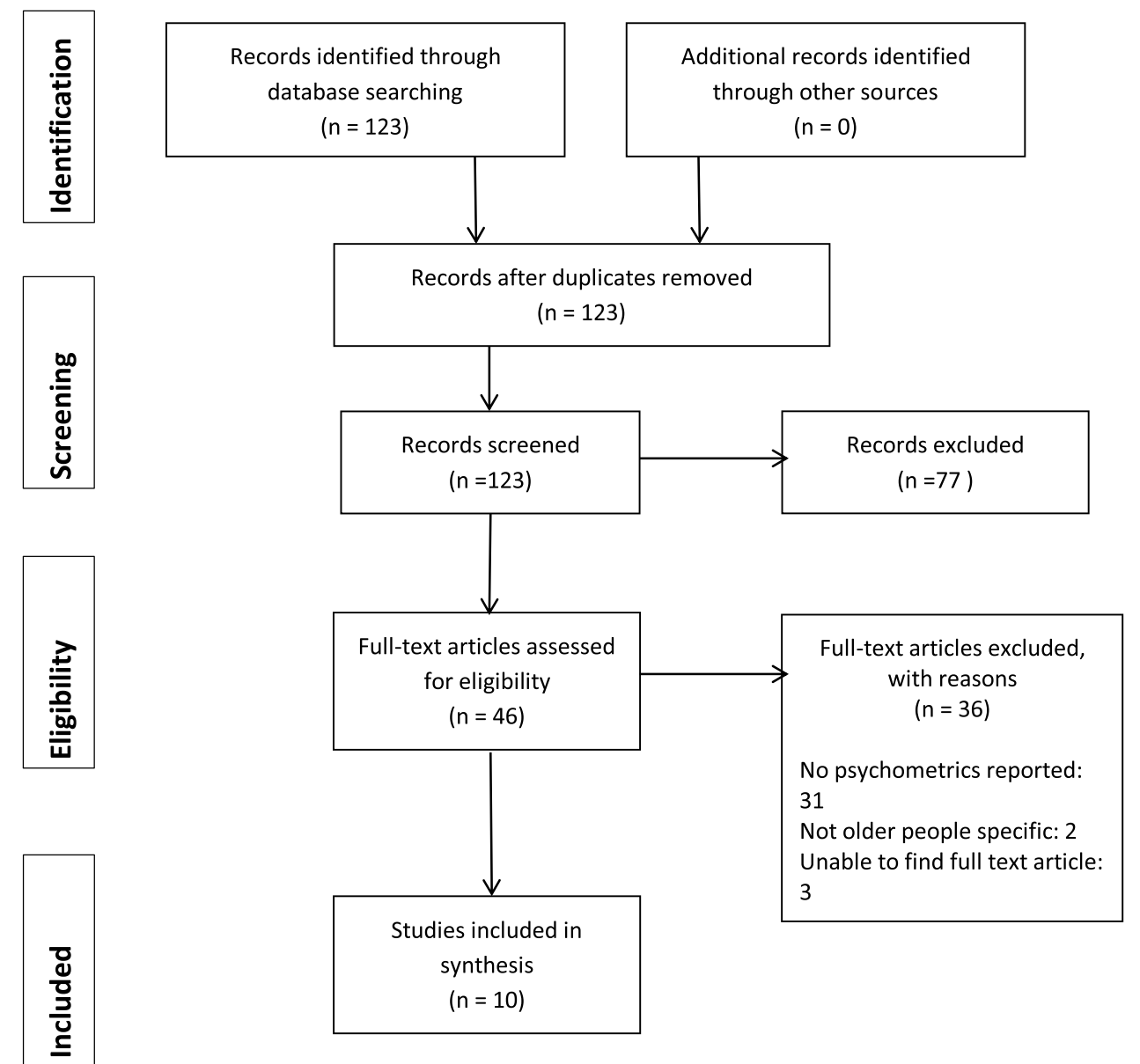

Figure 1 PRISMA diagram of screening process

articles included in this review (Heisel and Flett, 2016; O'Rourke et al., 2018). One article reported on the use of the 5-item World Health Organization Well-being scale as a measure of suicide ideation in older people (Awata et al., 2007), while three articles were single psychometric reports on a novel scale developed by the authors: Will to Live (Carmel, 2017); Triggers of Suicidal Ideation Inventory (TSII; Lee et al., 2017); and the Ultra-Short Suicidal Ideation Inventory (USSII; Nugent and Cummings, 2014). The final article reported on the combined use of existing scales, adapted for older adults: the Categories of Attitude Toward Death Occurrence (CADO) and the Schedule of Attitudes Toward Hastened Death - Senior (SAHD) scales (Durst et al., 2020).

The included articles represent a range of countries with three from the USA (Edelstein et al., 2009; Lutz et al., 2019; Nugent and Cummings, 2014), two from Canada (Heisel and Flett, 2016; Wadhwa and Heisel, 2019), and one each from Japan (Awata et al., 2007), Taiwan (Lee et al., 2017), Israel (Carmel, 2017), and Switzerland (Durst et al., 2020), with one further article using social media to recruit an international sample (O'Rourke et al., 2018). Measurement development and validation across the different scales were conducted with community, out-patient, and clinical samples ranging in age from 50 to 99 years. Most samples were over-represented by female participants (up to three quarters in some), and all studies that included information on the ethnicity of the sample were predominantly White, apart from studies conducted with Japanese (Awata et al., 2007) and Taiwanese (Lee et al., 2017) samples. We consider the measures in light of these sampling limitations in the Discussion.

\section{Administration and sampling}

Six of the articles reviewed were based on selfreported measures (Durst et al., 2020; Edelstein et al., 2009; Heisel and Flett, 2016; Lutz et al., 2019; O'Rourke et al., 2018; Wadhwa and Heisel, 2019), three used clinician interviews and interpretation to administer the measure and score responses (Awata et al., 2007; Carmel, 2017; Nugent and Cummings, 2014), while administration was not reported for the TSII (Lee et al., 2017). 
Table 1. Description of articles included in review

\begin{tabular}{|c|c|c|c|c|c|c|}
\hline $\begin{array}{l}\text { AUTHORS (YEAR) } \\
\text { AND COUNTRY OF } \\
\text { PUBLICATION }\end{array}$ & QUESTIONNAIRE & ADMINISTRATION & NUMBER OF ITEMS & $\begin{array}{l}\text { SAMPLE NUMBER } \\
\text { AND SETTING }\end{array}$ & $\begin{array}{l}\text { GENDER AND } \\
\text { ETHNICITY } \\
\text { BALANCE }\end{array}$ & AGE RANGE \\
\hline $\begin{array}{l}\text { Awata et al. (2007) } \\
\text { Japan }\end{array}$ & $\begin{array}{l}\text { WHO-5 Well-being } \\
\text { Index (WHO-5) }\end{array}$ & Clinician interview & 5 items & $\begin{array}{l}696 \text { - Community } \\
\text { sample }\end{array}$ & $\begin{array}{l}48.9 \% \text { female } \\
\text { no ethnicity data } \\
\text { reported }\end{array}$ & $\begin{array}{c}\text { Mean age } 75.7 \text { years } \\
\quad \text { (range not given) }\end{array}$ \\
\hline $\begin{array}{l}\text { Carmel (2017) } \\
\text { Israel }\end{array}$ & Will to Live & Clinician interview & $\begin{array}{l}5 \text { items } \\
6 \text { point Likert scale }\end{array}$ & $\begin{array}{l}868 \text { - Community } \\
\text { sample } \\
\text { three time points }\end{array}$ & $\begin{array}{l}46 \% \text { female } \\
\text { no ethnicity data } \\
\text { reported }\end{array}$ & 78-99 years \\
\hline $\begin{array}{l}\text { Durst et al. (2020) } \\
\text { Switzerland }\end{array}$ & $\begin{array}{l}\text { a. Categories of } \\
\text { Attitude toward } \\
\text { Death Occurrence } \\
\text { (CADO) } \\
\text { b. Schedule of } \\
\text { Attitudes Toward } \\
\text { Hastened Death } \\
\text { (SAHD)-Senior }\end{array}$ & Self-report & $\begin{array}{l}\text { a. } 6 \text { response cate- } \\
\text { gories - single item } \\
\text { response } \\
\text { b. } 20 \text { items, yes/no } \\
\text { response }\end{array}$ & $\begin{array}{l}101 \text { - Hospital inpa- } \\
\text { tient sample }\end{array}$ & $\begin{array}{l}67.3 \% \text { female } \\
\text { No ethnicity data } \\
\text { reported }\end{array}$ & 65 to $85+$ years \\
\hline $\begin{array}{l}\text { Edelstein et al. } \\
\quad(2009)^{1} \\
\text { USA }\end{array}$ & $\begin{array}{l}\text { Reasons for Living - } \\
\text { Older Adults } \\
\text { (RFL-OA) }\end{array}$ & Self-report & $\begin{array}{l}69 \text { items } \\
6 \text { point Likert scale }\end{array}$ & $\begin{array}{l}181 \text { - Clinical mental } \\
\text { health setting }\end{array}$ & $\begin{array}{l}59 \% \text { female } \\
88 \% \text { White }\end{array}$ & 50 years + \\
\hline $\begin{array}{l}\text { Heisel and Flett } \\
\text { (2016) } \\
\text { Canada }\end{array}$ & $\begin{array}{l}\text { Geriatric Suicide } \\
\text { Ideation Scale } \\
\text { (GSIS) }\end{array}$ & $\begin{array}{l}\text { Self-report or clinical } \\
\text { interview }\end{array}$ & $\begin{array}{l}31 \text { items } \\
5 \text { point Likert scale }\end{array}$ & $\begin{array}{l}173 \text { - Community } \\
\text { sample }\end{array}$ & $\begin{array}{l}71 \% \text { female } \\
65 \% \text { born in } \\
\text { North America }\end{array}$ & $65-93$ years \\
\hline $\begin{array}{l}\text { Lee et al. (2017) } \\
\text { Taiwan }\end{array}$ & $\begin{array}{l}\text { Triggers of Suicidal } \\
\text { Ideation Inventory } \\
\text { (TSII) }\end{array}$ & Not reported & $\begin{array}{l}10 \text { items } \\
5 \text { point Likert scale }\end{array}$ & $\begin{array}{l}200 \text { outpatient } \\
\text { sample } \\
+14 \text { member } \\
\text { Delphi panel }\end{array}$ & $\begin{array}{l}67 \% \text { female } \\
\text { No ethnicity data } \\
\text { reported }\end{array}$ & $65-90$ years \\
\hline $\begin{array}{l}\text { Lutz et al. (2019) } \\
\text { USA }\end{array}$ & $\begin{array}{l}\text { RFL-OA shortened } \\
\text { version }\end{array}$ & Self-report & 30 items & $\begin{array}{l}199 \text { - Community } \\
\text { sample }\end{array}$ & $\begin{array}{l}65 \% \text { female } \\
98 \% \text { White }\end{array}$ & 65 years + \\
\hline $\begin{array}{l}\text { Nugent and } \\
\text { Cummings (2014) } \\
\text { USA }\end{array}$ & $\begin{array}{l}\text { Ultra-short suicidal } \\
\text { ideation scale } \\
\text { (USSIS) }\end{array}$ & Clinician interview & $\begin{array}{l}4 \text { items } \\
7 \text { point Likert scale }\end{array}$ & $\begin{array}{l}200-\text { Geriatric } \\
\text { in-patient } \\
\text { psychiatric unit }+ \\
\text { community mental } \\
\text { health center }\end{array}$ & $\begin{array}{l}\text { Site } 1: 73.2 \% \text { female } \\
95.7 \% \text { White } \\
\text { Site } 2: 65.3 \% \text { female } \\
74.3 \% \text { White; } 20.8 \% \\
\text { African American }\end{array}$ & 50-97 years \\
\hline
\end{tabular}




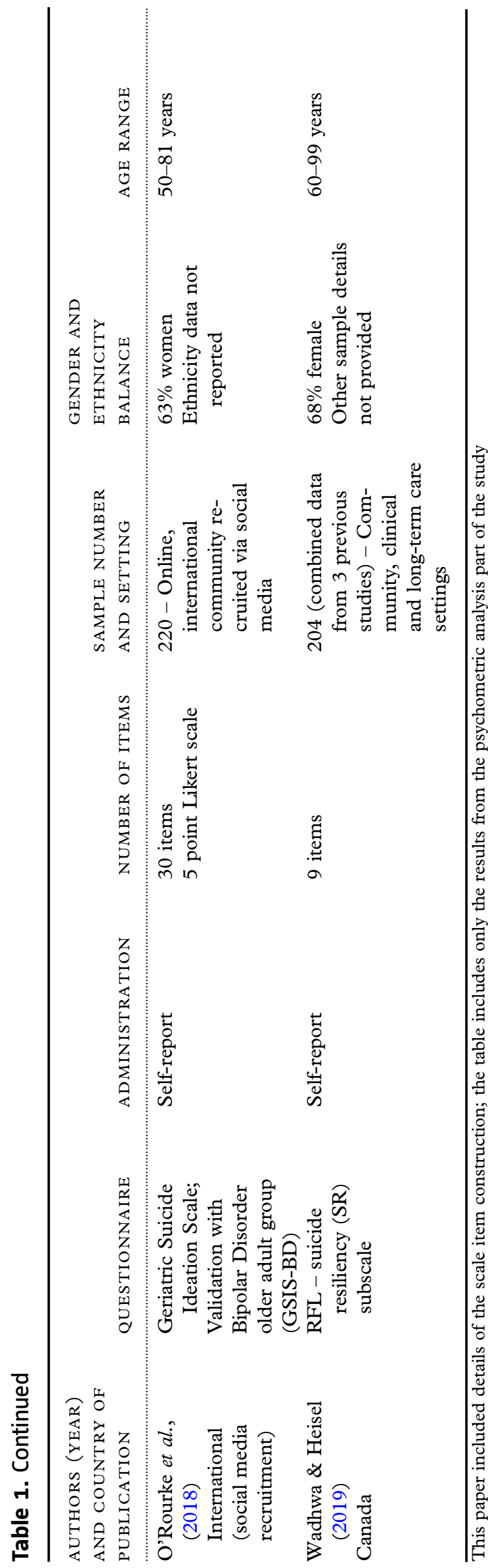

A number stated the purpose of their measures were to aid clinical detection of suicide ideation or assess risk factors for suicide in older adults, while some were presented as screening tools that could be used in more general assessment of well-being, referral decisions or support needs. However, the rationale for using exclusively community samples (Awata et al., 2007; Carmel, 2017; Heisel and Flett, 2016; Lutz et al., 2019; O'Rourke et al., 2017), mental health patient (either inpatient or outpatient) clinical samples (Durst et al., 2020; Edelstein et al., 2009; Lee et al., 2017; Nugent and Cummings, 2014), or a combination of both (Wadhwa and Heisel, 2019) in order to pilot and psychometrically test their measures was not presented in these articles.

\section{Scale development and design}

Item generation varied across articles. The will-tolive scale (Carmel, 2017) developed scale items through a series of earlier interviews with 25 older people and Edelstein et al., (2009) generated additional items for the RFL-OA scale using open-ended questions to older people on the things they felt influenced their wish to continue living. Awata et al., (2007) used an established scale, the WHO Wellbeing Index, to assess its usefulness in measuring suicide ideation among older adults. Durst et al., (2020) adapted two scales (CADO and SAHD) to measure the presence and intensity of suicide ideation in their sample. Meanwhile, Lutz et al., (2019) re-examined data from previous research and performed exploratory factor analyses to create a shortened version of the RFL scale before testing it psychometrically with a community sample recruited online. The remaining scales (Heisel and Flett, 2016; Nugent and Cummings, 2014; O'Rourke et al., 2018; Wadhwa and Heisel, 2019) were developed through a combination of reviews of existing literature and theory, clinical experience of the authors and, in the case of the TSII (Lee et al., 2017), the use of a Delphi panel.

\section{Theoretical frameworks}

Little information was provided in the papers reviewed on the process of item generation for scales reported. To better understand the approaches taken by the authors with respect to item generation, we assessed the theoretical frameworks adopted/ used in each paper.

Three scales (RFL; Will to Live and WHO-5 Well-being) were developed from the perspective of measuring factors that act as protective against suicide ideation or behavior, tending to reflect the concept of resiliency. Theoretically, it was argued that older adults can be less inclined to speak to 
Table 2. Quality assessment criteria and details

\begin{tabular}{|c|c|c|c|c|}
\hline PROPERTY & DEFINITION & SCORE & $\begin{array}{l}\text { UMERICA } \\
\text { SCORE }\end{array}$ & QUALITY CRITERIA \\
\hline \multirow[t]{4}{*}{ Internal consistency } & \multirow[t]{4}{*}{$\begin{array}{l}\text { The extent to which items in a scale, } \\
\text { or subscale, are inter-correlated }\end{array}$} & + & 2 & $\begin{array}{l}\text { Factor analysis performed on adequate sample size }\left(7^{*} \# \text { items and }>100\right) \text { AND } \\
\text { Cronbach's alpha per dimension and Cronbach's alpha between } 0.70 \text { and } 0.95\end{array}$ \\
\hline & & ? & 1 & No factor analysis or doubtful design or method \\
\hline & & - & 0 & Cronbach's alpha $<0.70$ or $>0.95$ despite adequate design and method \\
\hline & & NR & 0 & Not reported \\
\hline \multirow{4}{*}{$\begin{array}{l}\text { Reliability (inter-rater; } \\
\text { repeated measure- } \\
\text { ment etc.) }\end{array}$} & \multirow{4}{*}{$\begin{array}{l}\text { The extent to which individuals can } \\
\text { be distinguished from each other }\end{array}$} & + & 2 & ICC or weighted Kappa $\geq 0.70$ \\
\hline & & ? & 1 & Doubtful design or method \\
\hline & & - & 0 & ICC or weighted Kappa $<0.70$ despite adequate design and method \\
\hline & & NR & 0 & Not reported \\
\hline \multirow[t]{4}{*}{ Content validity } & \multirow[t]{4}{*}{$\begin{array}{l}\text { The extent to which the construct is } \\
\text { adequately represented by the } \\
\text { items included in the instrument }\end{array}$} & + & 2 & $\begin{array}{l}\text { A clear description is provided of the study aim(s), the target population, the concepts } \\
\text { being measured, and the item selection AND target population and (investigators OR } \\
\text { experts) were involved in item selection }\end{array}$ \\
\hline & & ? & 1 & $\begin{array}{l}\text { A clear description of above mentioned aspects is lacking OR only target population } \\
\text { involved OR doubtful design or method }\end{array}$ \\
\hline & & - & 0 & No target population involvement \\
\hline & & NR & 0 & Not reported \\
\hline \multirow[t]{4}{*}{ Criterion validity } & \multirow{4}{*}{$\begin{array}{l}\text { The extent to which the instrument } \\
\text { shows predictive and concurrent } \\
\text { validity (i.e. Gold standard) }\end{array}$} & + & 2 & $\begin{array}{l}\text { Convincing arguments that gold standard is gold AND correlated with gold standard at } \\
\geq 0.70\end{array}$ \\
\hline & & ? & 1 & No convincing arguments that gold standard is "gold" OR doubtful design or method \\
\hline & & - & 0 & Correlation with gold standard $<0.70$, despite adequate design or methods \\
\hline & & NR & 0 & Not reported \\
\hline \multirow[t]{4}{*}{ Construct validity } & \multirow{4}{*}{$\begin{array}{l}\text { The extent to which scores on the } \\
\text { instrument relate to other mea- } \\
\text { sures in a manner that is consistent } \\
\text { with theoretically derived hypoth- } \\
\text { eses concerning the concepts that } \\
\text { are being measured }\end{array}$} & + & 2 & $\begin{array}{l}\text { Specific hypotheses were formulated and at least } 75 \% \text { of the results are in accordance } \\
\text { with these hypotheses }\end{array}$ \\
\hline & & ? & 1 & Doubtful design or method \\
\hline & & - & 0 & $<75 \%$ of hypotheses were confirmed despite adequate design and methods \\
\hline & & NR & 0 & Not reported \\
\hline \multirow[t]{4}{*}{ Responsiveness } & \multirow{4}{*}{$\begin{array}{l}\text { The ability of the instrument to } \\
\text { detect clinically important changes } \\
\text { over time }\end{array}$} & + & 2 & SDC or SDC $>=$ MIC OR MIC outside the LOA OR RR $>1.96$ OR AUC $>0.70$ \\
\hline & & $?$ & 1 & Doubtful design or method \\
\hline & & - & 0 & $\begin{array}{l}\text { SDC or SDC }>=\text { MIC OR MIC equals or inside LOA OR RR }<=1.96 \text { or } \\
\text { AUC }<0.70 \text {, despite adequate design and methods }\end{array}$ \\
\hline & & NR & 0 & Not reported \\
\hline
\end{tabular}

In order to calculate a total score $+=2$ positive rating; ? = 1 indeterminate rating; $-=0$ negative rating; $0=$ no information available

Total score range $0-12$

*Item selection criterion only applied to original scale development studies

*** Cronbach's alpha calculated per dimension if the impostor phenomenon is conceptualized as multidimensional in the specific study

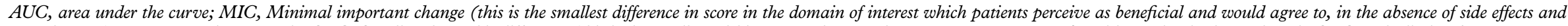

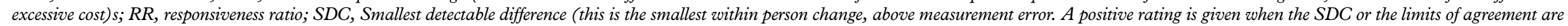
smaller than the MIC); SEM, standard error of measurement 
healthcare professionals about their mental health and may be reluctant to speak about negative emotions or experiences. Focusing on the factors that give them a reason to continue living (and by implication reasons for not attempting suicide) is thought to be a more appropriate means of detecting suicide risk in this population.

The older adult version of the RFL was adapted by Edelstein et al. (2009) to be administered to those aged over 60 years.. A community sample of older people who had previously considered suicide was asked to list the reasons that prevented them from attempting to take their own lives. This generated 41 unique items that had not previously been included in the RFL scale (for younger populations) and tended towards more reasons related to family, religion, and moral objections to suicide when compared to earlier versions.

Two further adaptations of the scale have been made, one as a shortened 30-item version (Lutz et al., 2019) and another using just items that reflected resiliency to suicide from the scale resulting in a nine-item measure (Wadhwa and Heisel, 2019). At 69 items, the original scale is argued to be excessively lengthy to be used with any frequency in most clinical settings (Lutz et al., 2019) and shortened versions that can measure suicide ideation with comparable accuracy should increase the use of screening tools.

The will-to-live scale, developed by Carmel (2017), is a five-item scale designed to measure subjective well-being among older adults using direct questions. Carmel argues that while subjective well-being scales can indicate positive factors in a person's life, they do not accurately assess risk of suicide or suicide ideation and that there is a preference among older people to be asked directly about their will to live. There are positive associations, but also unique variance, between subjective well-being measures and the will-to-live scale developed and presented in this article.

The WHO-5 aims to measure the presence of depression, physical health burden, and perceived social support. Awata et al. (2007) argue that these are the main drivers of suicide ideation in older adults and present findings from a Japanese translation of the scale in their paper

The remaining four scales (GSIS; SAHD/ CADO; TSII; USSIS) intended to measure suicide ideation more directly by focusing on the extent of thoughts of suicide or wishes to die that included both active and passive ideation (see Table 1 for full titles of all scales abbreviated here).

Developed by Heisel and Flett (2006), the GSIS is a 31-item scale designed to detect the unique factors associated with suicide ideation in older populations. Four subscales are included in the measure: suicide ideation, death ideation, loss of personal and social worth and, perceived meaning in life. The authors note that while past suicidal behavior is usually a significant predictive factor in determining future suicide risk, this is not always relevant in the context of older adults who are more likely to use lethal means on a first suicide attempt compared to younger populations. The purpose of the GSIS therefore is to detect more distal factors that may contribute to suicide ideation in older adults.

O'Rourke and colleagues assessed the GSIS in detecting suicide ideation in older adults with diagnosed bipolar disorder (BPD). This group was chosen because of the known increased risk of suicidal behavior in adults with BPD - particularly in those who have lived with a diagnosis for a longer period of time. Using social media to recruit 220 participants this study found that the four subscales of the GSIS reliably measured suicide ideation among this population.

Durst et al. (2020) adapted two scales (SAHD and CADO) designed to measure passive and active wish to die in older populations. Based on a scale initially developed to measure the wish to die among patients with terminal illness, the authors adapted the SAHD for older adults, who are more likely to endorse passive suicide ideation alongside previously measured factors. The CADO offers a qualitative assessment of the strength of the wish to die in older people who score highly on the SAHD which assists in clinical decision making relating to prevention and intervention services.

The Triggers of Suicide Ideation Inventory (TSII) was developed as part of a large-scale, longitudinal, suicide prevention study for older people in Taiwan (Lee et al., 2017). This ten-item scale contains three subscales: emotional distress; childrelated and financial problems; and self-valuerelated concerns. Developed for use in primary care settings, the TSII was designed as a means of screening early signs of suicide ideation in older people to promote early intervention and/or prevention measures being offered.

The Ultra-Short Suicide Ideation Scale (USSIS) is a four-item scale designed for use by a range of professionals who work with older people to screen for potential suicide ideation (Nugent and Cummings, 2014). The intention behind the development of this scale was to create an easy-to-use screening tool that was short enough not to place undue burden on healthcare professionals in order to increase suicide ideation screening in older populations. Development of this scale was consistent 
with the argument made by Carmel (2017) in that older people have a preference for direct questions relating to their potential suicide ideation.

\section{Psychometric properties}

Full details of the psychometric properties, and where they rank in our quality assessment, are given in Tables 2 (criteria) and 3 (quality assessment scores). Overall, the scales demonstrated good levels of internal consistency through calculation of Cronbach's alpha. Additional measures of reliability (repeated measures, Kappa, ICC, etc.) were only reported for one scale (TSII; Lee et al., 2017) where high indicators of test-retest reliability were reported for follow-up data collection with 30 randomly selected participants.

Most of the scales reviewed scored low on the content validity score in our quality assessment criteria. This was largely due to a lack of involvement of older people in identifying items for the scales or in adaptations of existing scales. While most scales had expert involvement in item development, only the original RFL (Edelstein et al., 2009) and the Will to Live (Carmel, 2017) tested the appropriateness of scale items with a pilot sample of older people. All other scales were developed through literature review or expert opinion without additional input from older adults.

Criterion validity was assessed as meeting the highest quality assessment score in all but two articles reviewed (WHO-5; Awata et al., 2007; TSII; Lee et al., 2017). These articles failed to assess validity of their scales against a standardized "gold standard" measure of suicide ideation either for older people or a wider population sample (as per the quality assessment tool, see Table 2). The other scales were compared to a range of additional measures including a series of subjective well-being measures (Will to Live; Carmel, 2017; GSIS; O'Rourke et al., 2018), the WHO quality of life index (SAHD/CADO; Durst et al., 2019), measures of previous suicide behavior (RFL; Edelstein et al., 2009; Lutz et al., 2019; Wadhwa and Heisel, 2019; GSIS; Heisel and Flett, 2016; O'Rourke et al., 2018), and clinician-rated suicide ideation after patient interview (USSII; Nugent and Cummings, 2014).

Quality assessment scores for construct validity were variable across the seven scales. Both the RFLOA (Edelstein et al., 2009) and GSIS (in Bipolar Disorder) (O'Rourke et al., 2018) scales were assessed as high on construct validity in terms of both discriminant and convergent validity measurements. Psychometric statistics for construct validity were not reported for either the will-to-live scale (Carmel, 2017) or the TSII (Lee et al., 2017). All other articles reported some results but did not generate specific hypotheses or it was unclear if the hypotheses stated for individual scale development studies were fully met (i.e. $>75 \%$ ).

Suicide ideation was assessed using the Beck SSI (Edelstein et al., 2009; Heisel and Flett, 2016; Lee et al., 2017; Wadhwa and Heisel, 2019), or clinicianrated psychological interview (Nugent and Cummings, 2014). Lutz et al. (2019) also compared scores on the RFL-OA shortened version to the GSIS to assess construct validity for suicide ideation, as did O'Rourke et al. (2018) in their validation of the GSIS for older adults with Bipolar Disorder and Wadhwa and Heisel (2019) in validating the resiliency subscale of the RFL-OA. Past history of suicidal behavior was also measured in three of the included studies with single- or two-item scales (Edelstein et al., 2009; Heisel and Flett, 2016) or in the case of the USSIS (Nugent and Cummings, 2014) through clinician interview.

Depression was measured against the CESD Depression scale (Lutz et al., 2019), Beck Depression Inventory (Edelstein et al., 2009), or the Geriatric Depression Scale (Awata et al., 2007; Carmel, 2017; Durst et al., 2020; Heisel and Flett, 2016; Lee et al., 2017; Nugent and Cummings, 2014; Wadhwa and Heisel, 2019). While some assessed their scales against psychological well-being (Heisel and Flett, 2016; Wadwha and Heisel, 2019) and/or subjective well-being (Carmel, 2017; Durst et al., 2020; Heisel and Flett, 2016; Wadhwa and Heisel, 2019) or satisfaction with life (O'Rourke et al., 2018).

Additional comparative measures included measures of physical functioning (Awata et al., 2007; Edelstein et al., 2009; Heisel and Flett, 2016; Lutz et al., 2019), general physical health (Carmel, 2017; Heisel and Flett, 2016; Lutz et al., 2019; O'Rourke et al., 2018; Wadhwa and Heisel, 2019), hopelessness (Heisel and Flett, 2016; Lutz et al., 2019; Wadhwa and Heisel, 2019), and loneliness (Carmel, 2017; Heisel and Flett, 2016; Lee et al., 2017).

O'Rourke et al., (2018) also assessed the psychometric properties of the GSIS (in Bipolar Disorder) against theoretically significant related factors for individuals with BPD who have a history of suicide behavior, including measures of medication adherence, sleep problems, and alcohol use.

\section{Discussion}

Globally, older people are at increased risk of dying by suicide when compared to other age groups (WHO, 2019). This is largely due to the use of more lethal methods and a tendency to either not seek, or not be offered, therapeutic intervention for mental health difficulties (Frost et al., 2018). 


\section{Table 3. Quality assessment scores for each article reviewed}

\begin{tabular}{|c|c|c|c|c|c|c|c|c|c|c|c|c|c|c|}
\hline \multirow[b]{2}{*}{$\begin{array}{l}\text { INSTRUMENT } \\
\text { a. Categories of } \\
\text { Attitude toward } \\
\text { Death Occurrence } \\
\text { (CADO) } \\
\text { b. Schedule of Attitudes } \\
\text { Toward Hastened Death } \\
\text { (SAHD) - Senior }\end{array}$} & \multirow{2}{*}{$\begin{array}{l}\text { AUTHORS } \\
\quad(\text { YEAR })\end{array}$} & \multicolumn{2}{|c|}{$\begin{array}{c}\text { INTERNAL } \\
\text { CONSISTENCY }\end{array}$} & \multicolumn{2}{|c|}{ RELIABILITY } & \multicolumn{2}{|c|}{$\begin{array}{l}\text { CONTENT } \\
\text { VALIDITY }\end{array}$} & \multicolumn{2}{|c|}{$\begin{array}{l}\text { CRITERION } \\
\text { VALIDITY }\end{array}$} & \multicolumn{2}{|c|}{$\begin{array}{l}\text { CONSTRUCT } \\
\text { VALIDITY }\end{array}$} & \multicolumn{2}{|c|}{ RESPONSIVENESS } & $\begin{array}{c}\text { TOTAL } \\
\text { QA } \\
\text { SCORE } \\
5\end{array}$ \\
\hline & & + & 2 & NR & 0 & - & 0 & + & 2 & $?$ & 1 & NR & 0 & \\
\hline $\begin{array}{l}\text { Geriatric Suicide } \\
\text { Ideation Scale } \\
\text { (GSIS) }\end{array}$ & $\begin{array}{l}\text { Heisel and } \\
\text { Flett (2016) }\end{array}$ & + & 2 & NR & 0 & $?$ & 1 & + & 2 & $?$ & 1 & $?$ & 1 & 7 \\
\hline $\begin{array}{l}\text { GSIS; Bipolar } \\
\quad \text { disorder specific }\end{array}$ & $\begin{array}{l}\text { O'Rourke et al. } \\
\text { (2018) }\end{array}$ & + & 2 & NR & 0 & $?$ & 1 & + & 2 & + & 2 & NR & 0 & 7 \\
\hline $\begin{array}{l}\text { Reasons for } \\
\text { Living - Older } \\
\text { adults (RfL-OA) }\end{array}$ & $\begin{array}{l}\text { Edelstein et al. } \\
\text { (2009) }\end{array}$ & - & 0 & NR & 0 & + & 2 & + & 2 & + & 2 & NR & 0 & 6 \\
\hline $\begin{array}{l}\text { RfL - OA (Suicide } \\
\quad \text { resiliency subscale) }\end{array}$ & $\begin{array}{l}\text { Wadhwa and } \\
\text { Heisel } \\
(2019)\end{array}$ & + & 2 & NR & 0 & - & 0 & + & 2 & + & 2 & $?$ & 0 & 6 \\
\hline $\begin{array}{l}\text { RfL - OA; Shortened } \\
\text { version }\end{array}$ & $\begin{array}{l}\text { Lutz et al. } \\
\quad(2019)\end{array}$ & + & 2 & NR & 0 & - & 0 & + & 2 & $?$ & 1 & NR & 0 & 5 \\
\hline $\begin{array}{l}\text { Triggers of Suicidal } \\
\text { Ideation Inventory }\end{array}$ & $\begin{array}{l}\text { Lee et al. } \\
\quad(2017)\end{array}$ & + & 2 & + & 2 & - & 0 & NR & 0 & NR & 0 & + & 2 & 6 \\
\hline $\begin{array}{l}\text { Ultra-short Suicidal } \\
\text { Ideation Inventory }\end{array}$ & $\begin{array}{l}\text { Nugent and } \\
\text { Cummings } \\
(2014)\end{array}$ & + & 2 & NR & 0 & - & 0 & + & 2 & $?$ & 1 & + & 2 & 7 \\
\hline $\begin{array}{l}\text { WHO-5 Well-being } \\
\text { Index }\end{array}$ & $\begin{array}{l}\text { Awata et al. } \\
\quad(2007)\end{array}$ & + & 2 & NR & 0 & NR & 0 & NR & 0 & $?$ & 1 & + & 2 & 5 \\
\hline Will to Live & Carmel (2017) & + & 2 & NR & 0 & - & 0 & + & 2 & NR & 0 & NR & 0 & 4 \\
\hline
\end{tabular}


A majority of older people who die by suicide have had a recent visit to a healthcare professional before taking their own lives, but only a small proportion had a mental health diagnosis at any time prior to their deaths (De Leo et al., 2013). This indicates a need to screen older people for suicide ideation across a range of health and social care settings in order to identify risk and be able to offer prevention services to this age group.

The purpose of this review was to identify existing measures that can be used to screen for, or identify, suicide ideation specifically in older age groups. Our search yielded seven individual scales published across ten articles. The need for older adult-specific measures was clear throughout however, and some scales (e.g. RFL) highlighted the unique factors of relevance to understanding suicide ideation in older populations. Psychometric properties of the measures included were generally high quality and demonstrated good rates of reliability and validity. Both the measures that focused on identifying risk factors associated with suicide and those that measured factors related to resilience showed comparable utility for clinical and healthcare screening. While there were relatively strong theoretical arguments for each of the measures reviewed, few contained any followup assessment of their acceptability to clinicians for more frequent use or their likelihood of being employed as part of a more generalized prevention of suicide focus for older people.

While age-appropriate measures appear to be needed, based on findings of different factors affecting wishes to live or to end one's life with age, there is a danger of perceiving "older people" as a single homogenous group. Prevalence estimates of suicide in older age groups have reported differences across cultural and ethnic groups (Canetto, 2017; Cukrowicz et al., 2011) suggesting a need for further nuance within measures of suicide ideation. There are also notable gender differences in rates of suicide in older people with older men being at significantly higher risk of using lethal methods of suicide (Neufeld and O'Rourke, 2009). Whether there are different indicators of suicide ideation between older men and women has yet to be examined within the research. One clear limitation in the development of the measures reviewed here is the disproportionality of the samples included in psychometric assessments. Almost all measures included a $90 \%$ or larger proportion of White participants, and most were over-represented by women. There was little consideration of broader social and environmental factors, such as financial security, access to healthcare, and living conditions, that could have additional influence on wishes to die or to continue with life alongside aspects of social support and perceived belongingness (Hodge, 2016).
A shift in focus from measuring risk to protective factors in determining suicide ideation in older people has been welcomed by some researchers (e.g. Deuter et al., 2016). This is based on evidence that identifies social connectedness and a feeling of belonging as key factors in older people reporting reasons for not attempting or thinking about suicide (Joiner, 2005). The measures reviewed in this study that focus on positive resiliency factors have shown good levels of reliability and validity in assessing suicide ideation in older people. However, the studies reviewed did not attempt to compare scores on their measures with actual outcomes for participants, and it is not clear if these measures accurately predict suicide ideation or behavior. Edelstein et al. (2009) do suggest that such measures should be used alongside measures of suicide risk as a means of better predicting such outcomes.

One concern regarding a focus on positivity and/ or resilience in determining suicide risk in older adults is that it could lead to professionals dismissing less obvious signs of mental distress in this group. If there are indications of even minimal functional well-being, would this then unconsciously exclude older people from potentially necessary mental health intervention? Though limited, there is some evidence (Frost et al., 2018) that HCPs focus more on physical health symptoms when treating older patients and while acknowledging that there is a high incidence of mental health difficulties including depression, it tends to be de-prioritized due to normalization and available time - physical health issues are more immediate, likely to be treatable and fit more comfortably within the remit of the skills and qualifications of HCP staff.

Overall, the authors of the articles reviewed here recognized that measuring depression alone is insufficient to track suicide ideation among older adult populations and that there are unique factors that need to be considered in this group that may not have been identified in previous scales developed for use with younger populations. The need to be aware of potential cultural differences in admitting to mental health difficulties was raised by Lee et al. (2017) in their scale development article based in Taiwan, where they note a particular reluctance for older people to endorse scale items indicating depression. However, it is not clear from our review of this literature whether this is a country or culturespecific factor that needs to be considered in the use of such scales as most scales were developed with overwhelmingly White sample groups, despite being conducted in countries with considerable ethnic diversity (e.g. USA, Canada).

The value of short, or ultra-short, scales was put forward by a number of the authors of the scales included (e.g. Awata et al., 2007; Nugent and 
Cummings, 2014) arguing for the need to develop measures that can be realistically used within current healthcare settings in addition to normal services. While the logic that a 69-item scale (e.g. RFL-OA) would prohibit wider use in primary, and even clinical, settings, appears reasonable, none of the studies sought the opinions of HCPs for the type of scale they would be likely to use in practice.

Perceived burdensomeness is one factor in Joiner's theory that may contribute to the understanding of suicide ideation - an idea supported by previous studies (Cukrowicz et al., 2012). The concept of perceived burdensomeness has also been highlighted as a factor in need of independent consideration with regards to assisted suicide in those with severe mental health difficulties (Stoll et al., 2021). While the measures we reviewed frequently included questions on social connectedness and support, none fully engaged with the theoretical issue of burdensomeness.

In addition to the points discussed above in relation to sampling in the development of the reviewed measures, there were a number of common limitations that should also be considered if any of the measures are to be used in healthcare settings. Firstly, none of the articles actively included older people themselves in the development of the measures or items to be included. Some (e.g. Carmel, 2017; Edelstein et al., 2009) based their item development partly on interviews or surveys with older people to determine relevant factors for inclusion, but there was no further involvement of older people beyond this for any of the measures. Secondly, the variation in settings and populations chosen for initial psychometric testing of the measures means it is not clear if these scales can be applied to community, residential and inpatient groups consistently or if they are only relevant to those used in development of the scales. Finally, the lack of followup with healthcare practitioners on their perspectives of the measures, how likely they would be to use them in practice, or what they would need for screening to become more commonplace means that the practical utility of these measures cannot be assessed with any degree of confidence.

This review has demonstrated a need for targeted screening measures to assess suicide ideation in older adults who are likely to display unique difficulties compared to younger populations who report thoughts of suicide. Nonetheless, our review has its own limitations that should be acknowledged. Our inclusion/exclusion criteria were necessarily narrow. We actively excluded papers that reported measures that were not explicitly designed for use in older adults; even if they had been successfully used in this group. It is possible that we missed some useful scales that would further understanding of older adult's suicide ideation through these inclusion/ exclusion criteria. Our searches were also limited to papers published in the English language. Given the range of countries represented in the scales reviewed, it is likely that some potentially useful papers may have been omitted. This also limited our understanding of cultural nuances in discussing and measuring suicide ideation.

A number of recommendations for future research are apparent from this review. Firstly, there is a need for further research to determine whether scales such as those presented here have potential to be used effectively across cultural groups in place of, or alongside, existing measures of depression, anxiety, or other mental health assessment tools. Currently, there is little research on how cultural differences in understandings of mental health, and suicide, affect how people interpret and answer questions on these issues, particularly in older populations. Likewise, it would be useful to determine which scales are used in primary and clinical settings and how they are perceived in terms of their usefulness, ease of use, and relevance to professionals to better understand the impact of the number of items on the take-up of more routine screening for suicide ideation in older populations. None of the studies we reviewed had actively included older people in the development of their measures. Greater attention to incorporating coproduction within these studies would benefit both the development and future use of such measures. Finally, previous qualitative studies have indicated perceived financial and caring burdensomeness is a likely factor in explaining older people's suicide ideation (Hafford-Letchfield et al., 2018). Given reported links between this and severe depression in some (Stoll et al., 2021), further research on how it manifests in older people, and how it can be addressed, is warranted.

While a number of measures have been developed over the past few decades to cater to this population, screening for either mental health problems, or for suicide risk is not routine in healthcare practice. The measures reviewed here showed good psychometric properties, although further research is needed to assess how likely they are to be used in practice. Evidence has shown that older people (and especially older men) are more likely to die by suicide on a first attempt compared to younger people and that they are least likely to have received a diagnosis of depression, or other mental health difficulty. It is apparent that appropriate screening measures, that both older adults and healthcare professionals find acceptable and useful, are needed to identify those most at risk so that preventative measures can be instigated where and when they are needed. 


\section{Conflict of interest}

None.

\section{Description of authors' roles}

HG co-designed the study and wrote the first draft of the full paper.

CR conducted the literature search, data extraction and contributed to the final draft of the paper.

TH-L co-designed the study and contributed to the final draft.

TE contributed to the final draft and assisted in the data extraction.

\section{References}

Almeida, O. P. et al. (2012). Factors associated with suicidal thoughts in a large community study of older adults. The British fournal of Psychiatry, 201, 466-472. DOI 10.1192/ bjp.bp.112.110130.

Awata, S. et al. (2007). Validity and utility of the Japanese version of the WHO-Five Well-Being Index in the context of detecting suicidal ideation in elderly community residents. International Psychogeriatrics, 19, 77-88. DOI 10.1017/ S1041610206004212.

Barak, Y., Cheung, G., Fortune, S. and Glue, P. (2020). No country for older men: ageing male suicide in New Zealand. Australasian Psychiatry, 28, 383-385. DOI 10. 1177/1039856220905304.

Bernier, S., Lapierre, S. and Desjardins, S. (2020). Social interactions among older adults who wish for death. Clinical Gerontologist, 43, 4-16. DOI 10.1080/07317115. 2019.1672846.

Canetto, S. S. (2017). Suicide: Why are older men so vulnerable? Men and Masculinities, 20, 49-70. DOI 10.1177/ $1097184 X 15613832$.

Carmel, S. (2017). The will-to-live scale: development, validation, and significance for elderly people. Aging and Mental Health, 21, 289-296. DOI 10.1080/13607863. 2015.1081149.

Conejero, I., Olie, E., Courtet, P. and Calati, R. (2018). Suicide in older adults: current perspectives. Clinical Interventions in Aging, 13, 691-699. DOI 10.2147/CIA. S130670.

Conwell, Y., Van Orden, K. and Caine, E. D. (2011). Suicide in older adults. The Psychiatric Clinics of North America, 34, 451-ix. DOI 10.1016/j.psc.2011.02.002.

Cukrowicz, K. C., Cheavens, J. S., van Orden, K. A., Ragain, R. M. and Cook, R. L. (2011). Perceived burdensomeness and suicide ideation in older adults. Psychology and Aging, 26, 331-338. DOI 10.1037/a0021836.

Cukrowicz, K. C., Jahn, D. R., Graham, R. T., Poindexter, E. K. and Williams, R. B. (2012). Suicide risk in older adults: evaluating models of risk and predicting excess zeros in a primary care sample. Fournal of Abnormal Psychology, 122, 1021-1030. DOI 10.1037/ a0034953.
De Leo, D., Draper, B. M., Snowden, J. and Kolves, K. (2013). Suicides in older adults: a case-control psychological autopsy study in Australia. Fournal of Psychiatric Research, 47, 980-988. DOI 10.1016/j.jpsychires. 2013.02.009.

Deuter, K., Proctor, N., Evans, D. and Jaworski, K. (2016). Suicide in older people: revisioning new approaches. International fournal of Mental Health Nursing, 25, 144-150. DOI 10.1111/inm.12182.

Durst, A.-V. et al. (2020). Wish to die in older patients: development and validation of two assessment instruments. Fournal of the American Geriatrics Society, 68, 1202-1209. DOI 10.1111/jgs.16392.

Edelstein, B. A. et al. (2009). Development and psychometric evaluation of the Reasons for Living - Older Adults scale: a suicide risk assessment inventory. The Gerontologist, 46, 736-745. DOI 10.1093/geront/gnp052.

Frost, R., Beattie, A., Bhanu, C., Walters, K. and BenSchlomo, Y. (2018). Management of depression and referral of older people to psychological therapies: a systematic review of qualitative studies. British fournal of General Practice, 69, e171-e181. DOI 10.3399/ bjgp19X701297.

Gleeson, H., Hafford-Letchfield, T., Quaife, M., Collins, D. A. and Flynn, A. (2018). Preventing and responding to depression, self-arm and suicide in older people living in long term care settings: a systematic review. Aging and Mental Health, 23, 1467-1477. DOI 10.1080/ 13607863.2018.1501666.

Hafford-Letchfield, T. et al. (2018). He just gave up': an exploratory study into the perspectives of paid carers on supporting older people living in care homes with depression, self-harm, and suicide ideation and behaviours. Ageing and Society, 40, 984-1003. DOI 10.1017/ S0144686X18001447.

Heisel, M. J. and Flett, G. L. (2016). Investigating the psychometric properties of the Geriatric Suicide Ideation Scale (GSIS) among community residing older adults. Aging and Mental Health, 20, 208-211. DOI 10.1080/ 13607863.2015.1072798.

Hodge, G. (2016). Suicide in an ageing UK population: problems and prevention. Quality in Ageing and Older Adults, 17, 218-228. DOI 10.1108/QAOA-05-2015-0022.

Joiner, T. (2005). Why People Die by Suicide. Cambridge, MA: Harvard University Press.

Lachman, V. D. (2015). Voluntary stopping of eating and drinking: an ethical alternative to physician-assisted suicide. Medsurg Nursing, 24, 56-59.

Lee, S.-H., Tsai, Y.-F., Wang, Y.-W., Chen, Y.-J. and Tsai, H. H. (2017). Development and psychometric testing of the triggers of Suicidal Ideation Inventory for assessing older outpatients in primary care settings. International Fournal of Geriatric Psychiatry, 32, 1114-1121.

Lutz, J., Edelstein, B., Katz, E. and Gallegos, J. V. (2019). A shortened version of the Reasons for Living Older Adults scale for clinical and research utility. The Gerontologist, 59, e241-e247. DOI 10.1093/geront/gny009.

Mezuk, B., Rock, A., Lohman, M. C. and Choi, M. (2014). Suicide risk in long-term care facilities: a systematic review. International fournal of Geriatric Psychiatry, 29, 1198-1211. DOI 10.1002/gps.4142. 
Moher, D., Liberati, A., Tetzlaff, J. and Altman, D. G. (2009). Preferred reporting items for systematic reviews and meta-analyses: the PRISMA statement. BMF, 339, b2535.

Monforte-Royo, C., Villavicencio-Chávez, C., Tomás-Sábado, J. and Balaguer, A. (2011). The wish to hasten death: a review of clinical studies. Psycho-Oncology, 20, 795-804. DOI 10.1002/pon.1839.

Neufeld, E. and O'Rourke, N. (2009). Impulsivity and hopelessness as predictors of suicide-related ideation among older adults. The Canadian fournal of Psychiatry, 54, 684-692.

Nock, M. K. et al. (2008). Cross-national prevalence and risk factors for suicidal ideation, plans and attempts. The British Fournal of Psychiatry, 192, 98-105. DOI 10.1192/bjp.bp. 107.040113.

Nugent, W. R. and Cummings, S. (2014). A validity and measurement equivalence study of the Ultra Short Suicide Ideation Scale with older adults. Fournal of the Society for Social Work and Research, 4, 439-459. DOI 10.1086/679225.

O'Riley, A. A., Van Orden, K. A., He, H., Richardson, T. M., Podgorski, C. and Conwell, Y. (2014). Suicide and death ideation in older adults obtaining aging services. The American fournal of Geriatric Psychiatry, 22, 614-622.

O'Rourke, N. et al. (2018). Psychometric validation of the Geriatric Suicide Ideation Scale (GSIS) amongst older adults with bipolar disorder. Aging and Mental Health, 22, 794-801. DOI 10.1080/13607863.2017.1317333.

Pfaff, J. J. and Almeida, O. P. (2005). Detecting suicidal ideation in older patients: identifying risk factors within the general practice setting. The British fournal of General Practice, 55, 269-273.
Stanley, I. H., Hom, M. A., Rogers, M. L., Hagan, C. R. and Joiner, T. E. Jr. (2016). Understanding suicide among older adults: a review of psychological and sociological theories of suicide. Aging and Mental Health, 20, 113-122. DOI 10.1080/13607863.2015.1012045.

Stoll, J., Ryan, C. J. and Trachsel, M. (2021). Perceived burdensomeness and the wish for hastened death in persons with severe and persistent mental illness. Frontiers in Psychiatry, 11, 532817. DOI 10.3389/fpsyt/ 2020.532817.

Terwee, C. B., Mokkink, L. B., Knol, D. L., Ostelo, R. W. J. G., Bouter, L. M. and de Vet, H. C. W. (2012). Rating the methodological quality in systematic reviews of studies on measurement properties: a scoring system for the COSMIN checklist. Quality of Life Research, 21, 651-657. DOI 10.1007/s11136-011-9960-1.

Wadhwa, S. and Heisel, M. J. (2019). Enhancing the assessment of resiliency to suicide ideation among older adults: the development and initial validation of the Reasons for Living - Suicide Resiliency Scale (RFL-SR). Clinical Gerontologist, 43, 61-75. DOI 10.1080/07317115. 2019.1675840.

Wand, A. P. F., Peisah, C., Draper, B. and Brodaty, H. (2017). Understanding self-harm in older people: a systematic review of qualitative studies. Aging and Mental Health, 22, 289-298. DOI 10.1080/13607863.2017. 1304522 .

World Health Organisation (WHO). (2019). Mental health and substance use: Suicide data. Available at https://www.who.int/teams/mental-health-and-substanceuse/suicide-data; last accessed 9 December 2020 